\title{
Rimando en galego en Bos Aires: identidade na poesía de Avelino Díaz (1897-1971)
}

\author{
Galician Rhymes in Buenos Aires: Identity in the Poetry \\ of Avelino Díaz (1897-1971)
}

\author{
Benigno Fernández SALgado \\ Universidade de Vigo \\ Departamento de Filoloxía Románica \\ bfsalgado@gmail.com
}

[recibido 01/10/2014, aceptado 27/01/2015]

\begin{abstract}
RESUMO
Aínda que inspirado poeta, Avelino Díaz (1894-1971) continúa a ser un completo descoñecido na literatura do país para o que escribiu. Os seus libros, publicados en edición do propio autor en Bos Aires, non coñeceron unha segunda edición e, tanto as súas colaboracións xornalísticas coma os centos de poemas espallados pola variada prensa da colectividade galegoporteña, non foron nunca rastrexados e compilados de maneira sistemática. No ámbito académico, unha monografia (Freire Freire 2002), que contén unha escolma de cen poemas precedidos dunha introdución biográfica, é a única excepción a este estado de indiferenza. Esta contribución propón unha lectura en termos de identidade da vida e obra poética de Avelino Díaz servíndose a modo de guía do concepto operacional de "identificación" formulado por LePage e Tabouret-Keller (1985).
\end{abstract}

PaLABRas ChaVE: Poesía galega, Bos Aires, identidade, emigración, biografía.

\section{RESUMEN}

Aunque inspirado poeta, Avelino Díaz (1894-1971) sigue siendo un completo desconocido en la literatura del país para el que escribió. Sus libros, publicados en edición del propio autor en Buenos Aires, nunca tuvieron una segunda edición y, tanto sus colaboraciones periodísticas como los cientos de poemas publicados en la variada prensa de la colectividad gallegoporteña, jamás fueron rastreados ni compilados de manera sistemática. En el plano académico, una monografía (Freire Freire 2002), consistente en una selección de cien poemas precedidos de una presentación biográfica, es la única excepción a este estado de indiferencia. Esta contribución se propone llevar a cabo una lectura en términos de identidad de la vida y obra poética de Avelino Díaz sirviéndose para ello del concepto operativo de "identificación" apuntado por LePage y Tabouret-Keller (1985).

PALABRAS CLAVE: Poesía gallega, Buenos Aires, identidad, emigración, biografía.

\begin{abstract}
Even though Avelino Díaz (1894-1971) was an inspired poet, he remains a complete stranger to the literature of the country he wrote for. His books, self-published in Buenos Aires, haven't been re-edited and neither his journalistic articles nor his hundreds of poems have been systematically compiled. In the academic sphere, a biography (Freire Freire, 2002) is the only exception to this state of indifference. This contribution proposes a reading of his life and poetic works in terms of identity by using LePage and Tabouret Keller (1985) concept of "identification"
\end{abstract}

KEY WORDS: Galician poetry, Buenos Aires, identity, diáspora, biography.

Fernández Salgado, B. (2015): "Rimando en galego en Bos Aires: Identidade na poesía de Avelino Díaz (18971971)", Madrygal (Madr), 18, Núm. Especial: 81-93.

SUMARIO: 1. Introdución. 2. Identificación / Identificando grupos. 3. Acceso ós grupos. 4. Motivación / Motivo / Pulo / Ímpeto / Estímulo. 5. Capacidade / Aptitude / Habilidade / Talento. 6. Conclusións. 7. Referencias bibliográficas. 


\section{INTRODUCIÓN}

Comprenderme, comprendernos, comprender o mundo que nos rodea...

Estamos interesados en saber quen somos. Lemos, escoitamos, pensamos, rastrexamos o noso pasado e o dos outros, e de aí as preguntas que nos asaltan non só sobre a historia que construímos senón sobre os fins que nos moveron, sobre as posibilidades que nos abre, sobre os proxectos que nos propoñemos levar a cabo e sobre o seu sentido...

As posibilidades de chegar a comprender o existente están sempre limitadas polas circunstancias do aquí e agora en que investigamos. Isto é certo da biografía que pretendemos recuperar neste traballo, e do concepto de "identidade" que abordamos aquí a través da lectura dunha obra poética creada ó longo de varias décadas.

Debo recoñecer que no rescate dun legado esquecido, hai tanto de desexo de proxectar a historia cara ós demais e cara ó futuro como de indagación obxectiva nos residuos dun pasado cada vez menos recente. É un vago sentimento de que o traballo encerra en si algo da transcendencia que buscamos para as nosas vidas, de que pode ser útil e valioso para axudarnos a entender a nosa humanidade. En calquera caso, asumimos, na liña fenomenolóxica do apuntado por Martínez-Romero Gandos $(2005,2012)$, que os humanos, as persoas, somos produtos da nosa específica temporalidade, e que estamos destinados a producir en cada tempo e lugar unha resposta "singular, única e irrepetible".

Por que os versos de Avelino Díaz (AD) como obxecto de estudo ou reflexión? A resposta simple é por descubrir alguén cunha sensibilidade e unha obra poética que merece ser dada a coñecer. Pero, coma todo, a escolla foi froito de bastantes máis casualidades necesarias. Como investigadores somos libres para abordar os temas que nos interesen nas nosas carreiras académicas. No 2003, os poemas de $\mathrm{AD}$ chegáronme como agasallo da autora en forma de libro (Freire Freire 2002), mais as miñas preocupacións estaban daquela noutros lugares (no ámbito da publicidade e da comunicación social) e terían que pasar outros dez anos ata que fun convidado a dar unha conferencia sobre a poesía dun xornal local que estudara e editara previamente (Fernández Salgado 2007). En termos cronolóxicos, a vida e obra de AD procede dun pasado aínda non moi distante para a miña xeración. Sería coma o tempo dos meus avós: nace en 1897 e falece en 1971. Queda moi pouca xente viva que o coñecese en persoa pero haina, e buscalos e entrevistalos formou parte da preparación para este primeiro ensaio ${ }^{1}$. Finalmente, é claro para min que de non estar familiarizado co ámbito dos estudos culturais é probable que non xuntase a forza e ousadía precisa para acometer este traballo de exploración e rescate.

A segunda parte do título esixe unha pequena digresión teórica. Que imos entender por identidade? Ou, posto nos termos que introducimos no título, a que nos referiremos neste traballo cando falemos de "identidade"? Adiantaremos, simplemente por claridade expositiva, que dada a multidimensionalidade do concepto, a nosa idea foi a de investigar o discurso identitario dende unha posición construtivista radical (Vygotsky 1962, Glasersfeld 1995). Isto é, non tanto dende o esencialismo en aparencia implícito no substantivo identidade ("o estado ou feito de seguir sendo o mesmo") coma no da construción existencial que se expresa a través do verbo identificar(se). A identidade aparecería cando nos identificamos cos outros. Identificar implica recoñecer, verificar ou adoptar unha parte da identidade de algo ou de alguén. É algo que se pode "facer" (ou "tornar, converter en algo") e de aí o sufixo -ificar. No ámbito da sociolingüística foron Robert B. LePage e A. Tabourett-Keller,

\footnotetext{
${ }^{1}$ Agradezo a David Álvarez Carballido e Antón Santamarina; a José Martínez-Romero Gandos e Pilar Jeremías; e a Xosé Neira Vilas o tempo co que nos agasallaron a min e a miña muller, Carlota Eiros, este verán.
} 
no seu Acts of Identity, os que falaron das seguintes catro restricións ós nosos actos de identidade, isto é, ó que aspiramos a ser:

Our ability to get into focus with those with whom we wish to identify, however, is constrained (...). We can only behave according to the behavioural patterns of groups we find it desirable to identify with to the extent that:

\section{We can identify the groups}

We have both adequate access to the groups and ability to analyse their behavioural patterns

The motivation to join the groups is sufficiently powerful, and is either reinforced or reversed by feedback from the groups

We have the ability to modify our behaviour. (LePage e Tabourett-Keller 1985: 182; Fernández Salgado 1994: 27-46)

Nos intercambios lingüísticos, os falantes adoptan as linguas que cren que mellor caracterizan os roles sociais que procuran e que, nalgún momento das súas experiencias lingüísticas previas, estiveron ó seu alcance. Esa identificación motivada, maiormente consciente, acaba formando parte da nosa identidade social.

No que segue revisamos os versos e datos biográficos de $\mathrm{AD}$ coa intención de desvelar algunhas das parcelas da súa identidade. Para organizar o relato creamos catro seccións relacionadas coas restricións apuntadas: (i) identificación de grupos, (ii) acceso e análise de comportamentos, (iii) motivación e reforzo ou rexeitamento e (iv) habilidade para cambiar.

\section{IDENTIFICACIÓN / IDENTIFICAN- DO GRUPOS}

$\mathrm{O}$ individuo relaciónase co seu contorno e con outros individuos. Nesas relacións prodúcese o que se coñece como "identidade"; somos recoñecibles porque se supón que temos algo que non teñen outros, algo que nos "identifica". E, non obstante, o paradoxo da identidade é que necesita da alteridade, dos outros, para a súa existencia. Identificación significa facerse igual a outros: o individuo necesita facerse coma outros para poder ser recoñecido.

De quen fala $\mathrm{AD}$ nos seus poemas? Para quen fala? Con que ou con quen se identifica? A quen podemos identificar nos seus versos e rimas? Avelino fala de si mesmo, moitas veces, e ás veces case para si mesmo, diso non hai dúbida; pero falando do que entende como máis seu, fala dos outros, dos que quere como seus.

A súa voz é unha voz persoal, recoñecible, facilmente identificable. En canto o lemos con algo de vagar, é evidente que, ademais da lingua na que fala, ten o seu peculiar ritmo e acento, que deberiamos rebuscar, primeiro de nada, nas coplas, romances e poesía popular. O seu é un exercicio de memoria. Lémbrase dos seus, pretende ser fiel ós seus, e estes constitúen os grupos dos que se sente pertencer. As dedicatorias son sintomáticas disto que acabamos de dicir: Flor de retama, o primeiro, dedícao á súa nai, á súa muller e ós seus fillos. Pallaregas, o último en vida, á caste [galega] da que provén, á clase [traballadora] a que pertence, e, "en suma", dinos, ó seu pobo [galego e traballador].

O primeiro poema do primeiro libro pode servirnos para describir o ton, a melodía e o uso da rima dunha parte importante da súa lírica, a máis intimista e familiar, a poesía en galego e castelán que levaba publicando en revistas dende había década e media ${ }^{2}$. O poema en cuestión leva por título "Proa". Proa, como se sabe, é a parte dianteira da embarcación, a que marca a dirección, a que corta as augas do mar poético que debería cruzar. Di así (Díaz 1947a: 5):

Un decir suave y un susurro manso con algo de simple caricia y arrullo, como el arroyito que va sin descanso brindando al paisaje su leve murmullo.

\footnotetext{
${ }^{2}$ Nunca se apresurou en publicar. En varias ocasións na década dos vinte e trinta, a prensa anunciou que tiña varios libros en preparación. Flor da xesta anunciouse en Céltiga, Lonxanía no Galicia, mais ningún deles viu a luz.
} 
A voz do poeta, suave e mansa coma o murmurio dun regatiño, integrándose na ruidosa paisaxe lingüística e literaria do Bos Aires da posguerra mundial. Con só mencionar, como contraste, o "mar doce" do inmenso Río da Prata, que sería o referente xeográfico real máis próximo, a humilde e tranquilizadora imaxe á que o poeta acode confírelle ó cuarteto de presentación unha insólita grandeza lírica.

Todos probablemente concordamos en que as decisións e as escollas lingüísticas son a chave da poesía e do estilo. Avelino Díaz publicou este libro, Flor de Retama, en castelán en maio de 1943, e dous meses despois, Debezos, en galego. Cos datos que achega Freire Freire (2002: 51-52) pódese facer un cálculo aproximado das linguas das que se serviu para confeccionar a súa poesía. A obra en galego abranguería, grosso modo, 653 poemas. $\mathrm{O}$ total de poemas en castelán ascendería a uns 515 poemas. Aínda que os datos deban revisarse, parece ser que o noso Avelino foi un poeta prolífico abondo, autor dunha obra orixinal bilingüe importante, e, polo que se sabe, tradutor ocasional para o galego, portugués e italiano. É interesante comprobar que, como o propio AD confesa nun Inquérito de 1936 editado por Acuña Trabazo e Alonso Montero (2008), empezase escribindo "versitos" en castelán, pero que unha vez convencido de que debía facelo en galego acabase por asumir de maneira decidida a súa lingua materna como lingua literaria.

O que é significativo respecto da identificación dos grupos no caso da lírica en galego de Avelino é que "os galegos", dos que se torna nunha especie de bardo emulando a tradición céltica e o rol de Pondal, aparecen como destinatarios privilexiados e protagonistas de moitos dos seus poemas máis combativos e inspirados. Casar cunha mociña vasconavarra, cando só tiña 24 anos, e establecer, dende entón, vínculos familiares permanentes en español (sabemos por testemuños relatados que sempre falaba nesta lingua coa súa muller), non modificou, senón máis ben o contrario, exacerbou a súa actitude nacionalista de defensa da lingua e de todo canto atinxise ó pobo do que se sentía parte. A participación na organización das moi activas sociedades galegas do momento, co contacto solidario e permanente establecido con outros activistas e intelectuais da colectividade galega, explica a súa concienciación galeguista e progresista no melting pot que era Bos Aires.

\section{ACCESO ÓS GRUPOS}

Ter acceso ós grupos nos que un se quere recoñecer e capacidade para analizar os seus comportamentos son dous dos requisitos que LePage e Tabouret-Keller listan na segunda restrición da súa teoría de construción da identidade.

A idea é que un individuo pode chegar a ser alguén (i.e. ter identidade) se está entre o grupo do que pretende formar parte e é quen de ver os comportamentos do grupo e reproducilos coa súa impronta. Exemplificado de maneira vulgar, alguén que queira ser rapeiro debe andar entre a xente adecuada e aprender dela. Nas sociedades receptivas de inmigrantes, o emigrante forma cos que están nas mesmas condicións un grupo claramente diferenciado mentres a integración na cultura dominante non sexa efectiva. Os emigrantes galegos constituían o subgrupo máis marcado dentro da emigración española á Arxentina (sobre un 55\%), de maneira que os propios españois eran coñecidos metonimicamente como "gallegos". A incorporación ó vigoroso movemento societario da colectividade galega dos anos vinte e trinta comeza para $\mathrm{AD}$ en 1924, cando funda con varios paisanos, a Sociedad del Ayuntamiento de Meira.

Dende entón ata practicamente a súa morte, cando é enterrado no panteón social do Centro Gallego, a súa traxectoria vital estará marcada por esa idiosincrática socialización que facilitaban as máis de 300 sociedades galegas, moitas delas localistas, que, dende 1921 conseguiran agruparse nunha especie de supraorganización que aglutinaba un bo número delas baixo o nome de Federación de Sociedades Gallegas. Martínez-Romero Gandos (2005) na presentación da súa tese doutoral recórdanos as palabras de Ferrarotti (1970) sobre a interiorización da cultura:

Lo universal y lo singular no solamente se oponen sino que se re-asumen en un proceso dialéctico en constante movimiento. Este es el 
lugar de la temporalidad, allí donde el ser humano vive dramáticamente su tiempo. (...) El ser humano recibe una cultura, la aprehende, la interioriza para después producir una síntesis particular, su original movimiento histórico, su especial modo de respuesta. (1970: 7)

Todos recibimos unha lingua e unha cultura, primeiro do grupo máis próximo, a familia; logo da comunidade local en que vivimos, e finalmente da socialización diversa e multiforme á que nos conducen os camiños da vida. A poesía de $\mathrm{AD}$ pode ser explicada nestes termos. Xa dixemos que Avelino Díaz lle dedicara á familia o seu primeiro libro. O segundo, Devezos, porta estoutra dedicatoria reveladora do grupo co que se identifica e do valor para el máis prezado, a liberdade: "A todos os galegos que en Galicia, e fóra dela, loitan pola súa liberdade".

O sintomático aquí son as dúas Galicias. Avelino Díaz non era un exiliado cando marchara case de aventura co seu tío en 1910 con 12 anos, nin cando abandona Galicia definitivamente en 1920 con 22. Para 1936, cando comezan a chegar os primeiros exiliados da guerra, o emigrado Avelino, concienciado na década anterior de xornalismo amateur, é xa un comprometido activista, involucrado na causa galeguista e republicana. Quen participa nos Comités de Axuda á República, dirixe o Galicia, axuda a refundar A Nosa Terra e se incorpora á Irmandade Galega, deixaba de ser para o réxime franquista un inxenuo emigrante e pasaba a ser considerado inimigo declarado. A volta a España, para $\mathrm{AD}$, comezará a ser máis unha quimera de poeta ca unha posibilidade real. En Debezos, comeza a expresar ese futuro imposible neste fermoso "Zéjel” (Díaz 1947b: 9-10):

De Galicia, namorado topareime ben pagado, se nela son enterrado.
Pra tal sorte recadar

a Galicia lle hei cantar

con verbas de namorar.

Se hai algún trasfondo na obra de $\mathrm{AD}$ ese é o da emigración e os seus efectos e implicacións. "Emigrar", explica Martínez-Romero Gandos (2005: 13), "é a paradoxal apetencia do home por afastarse daquilo que de seguida ha de recoñecer como terriblemente necesario: a terra, cuxa distancia lle vai facer morrer de morriña, de soidade, de nostalxia, de saudade". No galego e mais no español, "exiliarse" refire non a intransitividade de emigrar, "un emigra", senón a aparente reflexividade dunha escolla condicionada: "un exíliase (a si mesmo)", un parece que decide ausentarse, pero faino obviamente compelido polas autoridades do país do que debe fuxir so pena de arriscar a vida ou a liberdade. A liberdade é aquí a noción central que separa os emigrantes forzados a emigrar dos anos anteriores á guerra, obrigados pola economía, pero en teoría libres para tentaren o retorno cando o desexasen, dos emigrados por mor das ideas que profesan que ven definitivamente coutada a volta á casa mentres durase a ditadura. Avelino Díaz, "hombre de conciencia clara y altos ideales, de conducta insobornable y modesto quehacer", como o describe Neira Vilas (1963), preferirá ser consecuente coa súa escolla de oposición ó franquismo e nunca voltará. A súa é a vez unha historia de emigración e (auto)exilio. Ora cantando á tristeza da separación e da ruptura de algo dificilmente suturable; ora experimentando a morriña a través do recordo da paisaxe e dos costumes (ambos vividos unha vez e agora só na memoria); ora sentindo a señardade das persoas e cousas máis queridas, tornada ás veces en dolorosa angustia existencial; ou sublimando o desexo de retornar aínda que só sexa na fantasía do voo de gaivotas e andoriñas, a súa poesía é de filiación migrante ${ }^{3}$.

${ }^{3}$ A parte da produción poética máis politizada e máis combativa que nos legou só se pode entender no contexto do contacto e relacións cos grupos galeguistas e republicanos de Bos Aires, que se reforzan coa chegada de Castelao, e en función da súa implicación en moitos dos proxectos emprendidos nas décadas dos corenta e cincuenta polas elites intelectuais da colectividade. Non é difícil comprobar a súa identificación con Castelao, a quen dedicou non menos de 35 poemas (Freire 1999). 
"Soma esvaída", poema escrito antes de 1936, é unha das 14 composicións que el escolle como representativas da súa lírica no seu envío a Filgueira Valverde (Acuña Trabazo e Alonso Montero 2008) e que insire na sección "Íntimas" de Debezos (Díaz 1947b: 80-81). A imaxe de que bota man $\mathrm{AD}$ nesta ocasión é a do emigrante que se perde no mundo, a do viaxeiro cuxa figura se esvae no horizonte. Esta é unha das moitas poesías en que se nos describe o estado anímico do eu/el poético. É á vez etopea e prosopopea, pois nela esboza a súa liñaxe poética, reivindicándose como "poeta do sentimento", equiparando os seus versos cos da vella escola, e igualándoos ós da lírica máis sentimental que a tradición romántica representaba (Díaz 1947b: 80):

Poeta do sentimento, com-os poetas de antano; iba detrás da ilusión, por vieiros iñorados

A distancia que o poeta emocional adopta escribindo sobre si en terceira persoa resulta cando menos chocante á vista do dito, pero enténdese perfectamente cando se constata que é do extravío e do desacougo existencial que calquera ser humano pode sentir do que nos fala o poema. Como viaxeiros, ou como emigrantes, recorrendo camiños á procura dos nosos particulares El Dorado, calquera de nós pode identificarse co suxeito poético. Perseguindo "a ilusión", as "ilusións", ansioso por ir sempre máis alá ("famento de lonxanías"), pisando camiños coñecidos ou intransitados, a voz poética acabará por recoñecer que non hai posibilidade de volver atrás e que é o destino final do viaxeiro tornarse "sombra esvaída", como se predica no título. É máis, se os camiños polos que un escolle transitar son "vieiros iñorados" (expresión repetida tres veces ó longo do poema), o consolo da presenza ou da compañía humanas será imposible. Nin sequera haberá alguén con quen cruzarse que poida doerse do viaxeiro (Díaz 1947b: 81):
Fuxiron d-él os ensonos

como fatos de paxaros

i-as surrisas nos seus beizos

esmorecidas ficaron.

Branquearon seus cabelos

coa neve dos desenganos;

deixaron de ser brilantes

os seus ollos azuados...

A alegoría da vida en tanto que camiño, omnipresente en toda a literatura occidental, facilmente rastrexable na hispánica (dende Manrique a Machado, que inspiran outros poemas seus), aparece desenvolvida aquí no contexto existencial do cantor que, como persoa adulta, ve naufragar as expectativas -posiblemente fantasías- de conseguir algo ou chegar a algures. Hai moitos poemas en $\mathrm{AD}$ nos que os personaxes aparecen en movemento pero é só neste, se lembramos ben, no que o poeta emigrante se recoñece a si mesmo decepcionado e perdido ${ }^{4}$. Co paso dos anos, ilusións, fantasías e soños comezan a esfarelarse. As promesas da emigración esborrállanse. Pouco importa que un tentase cabalgar cara a un país ignorado ou que tentase percorrer vieiros aínda máis ignorados, que experimentase "o misticismo das auroras" ou deprendese "os rezos sagros", pois é o paso inexorable e o poder corrosivo do tempo o que acaba devolvendo o emigrado á forma orixinaria do emigrante, a da "sombra esvaída", a sombra que desaparece sen deixar rastro. É a imaxe que se evoca nun dos poemas de Pallaregas titulado xustamente así, "Emigrantes", nos que os describe saíndo ás agachadas, como sombras de sombras (Díaz 1963: 73-74):

Ibanse como somas polo camiño adiante cos embrullos ó lombo, como somas que fuxen de sí mesmas, arrastre, lixadas polo amente, deixando somas horfas nos seus vales

"Soma esvaída" fala de desilusión. Quen nunca pareceu estar interesado polo "éxito", si

\footnotetext{
${ }^{4}$ En "Lusco-fusco", por exemplo, preséntasenos o eu poético camiño do encontro da amada. En "Amoranza" e "Galbana", invitándoa a que non fuxa e se vaia con el para o agro ou a descansar.
} 
experimenta, paradoxalmente, algo tan humano coma o fracaso ou o desengano. Cando escribe o poema, Avelino parece atravesar unha certa crise existencial, pero sabíase, como poeta, acompañado no sentimento que pretendía expresar. Recoñécese continuador dunha tradición, dunha xenealoxía poética coa que se identificaba espiritualmente, e de aquí que na primeira e na derradeira estrofa abrace "os poetas de antano". Sábese deles e arroupado por eles, e non mostra reparos en desmarcarse tanto dos modernos e da súa poesía de clixés (non hai "belidas fadas", nin "pazos encantados", nin "doídas princesas" modernistas) como, indirectamente, dos que se mostran alleos ó sufrimento e ó sentimento. A proba de que se embarca coa tradición e coas súas inquedanzas testemúñao a construción dos versos en que recrea a inxenuidade das ilusións primeiras (Díaz 1947b: 9), onde afloran reminiscencias do coñecido poema de Curros de 1885: "Do mar pola orela/ mireina pasar/ na frente unha estrela/ no bico un cantar/ (...)/ Ai dos que levan na frente unha estrela/ ai dos que levan no bico un cantar":

Levaba anceios na ialma, na fronte, soños dourados, nos beizos, ledas sorrisas, no peito, amores calados $i$ en meiguice de luceiros os ollos engaiolados.

Sexa polos seus gustos eclécticos ou pola diversidade de temas e estilos que aborda, AD ensaia na súa obra poética as liñas diverxentes das tres vertentes da nosa literatura decimonónica con resultados notables -nel ecoan Rosalía e a súa saudade, Curros e o seu espírito cívico, e o Pondal épico tinguidos da súa peculiar sensibilidade cara ó social e ó cósmico. É así mesmo probable que o contacto con poetas arxentinos e iberoamericanos, cuxas voces dende esta banda do Atlántico son máis difíciles de discernir, o inspirasen nalgunhas composicións. Podemos arriscar, por exemplo, unha hipótese en relación cun dos poemas publicados en Debezos. Se na composición anterior parecía mofarse da imaxinería modernista, non parece, pola contra, descartable a inspiración de Rubén Darío para un poema coma "Prego", composto antes de 1936. $\mathrm{Na}$ "Letanía de Nuestro Señor Don Quijote", Rubén Darío evoca a figura heroica e triste do Quixote e "roga"5; en "Prego", Avelino Díaz invoca "con fonda tristura" a Deus e "prega" (1947b: 96-97):

Rey de los hidalgos, señor de los tristes, que de fuerza alientas y de ensueños vistes (...)

¡Ruega por nosotros, hambrientos de vida, con el alma a tientas, con la fe perdida, llenos de congojas y faltos de sol, (...)

¡Ruega por nosotros, que necesitamos las mágicas rosas, los sublimes ramos (...)

\author{
Deus, que estás no ceio, \\ veño aquí a pregarche \\ (...) \\ polos que se foron \\ e nunca volveron \\ polos que inda viven a que xa choraron \\ (...) \\ Polos que viviron en longo tormento \\ e hoxe están calados \\ (...)
}

Non é obxecto deste artigo disertar sobre os mecanismos psicolóxicos que conducen a analoxías conceptuais e similitudes formais entre artistas aparentemente distantes. $\mathrm{O}$ que si sabemos é que os poetas se senten atraídos por outros poetas. Rubén Darío e Avelino Díaz

${ }^{5}$ O poeta nicaraguano publica Cantos de vida y esperanza en Madrid en 1905. Nel inclúese "Letanía de Nuestro Señor Don Quijote" (pp. 461-464), o poema aquí a colación. Díez de Revenga (2005: 713) comenta deste poema: "el Quijote homenajeado por Rubén es singular, y se ajusta, como hemos de ver, muy bien a su espíritu en aquellos primeros años del siglo XX, su forma de pensar e incluso su ideología al revelarse en sus estrofas una evidente crítica social y ética frente a lo establecido, frente a la ficción de los homenajes, frente a los engaños". 
coinciden no idealismo e na súa paixón polo elevado e polo grave, mais podería tratarse igualmente do eco dun eco poético. Xerardo Álvarez Limeses, con quen Avelino compartía vea poética e afinidades temáticas e emocionais, acababa de publicar o seu único libro de poesía Antre dous séculos, con prólogo de Castelao, en 1934, no que incluíra o poema de título "Orazón". Quen pode arriscarse a postular influencias coas limitadas evidencias que temos? Rezar, orar, pregar, rogar... son tan universais coma a mesma poesía. A base anafórica do "Ora pro nobis" ("Roga por nós") e o ton propio da "ladaíña", coas súas enumeracións e repeticións, formaban parte da cultura dunha sociedade marcadamente relixiosa e practicante como era a galega de principios do século XX.

\section{MOTIVACIÓN / MOTIVO / PULO / ÍMPETO / ESTÍMULO}

Ter motivacións para querer unirse a un grupo constitúe o terceiro factor nos procesos de identificación descritos polo profesor LePage (LePage e Tabouret-Keller 1985; Fernández Salgado 1994). Nesta sección estúdanse as motivacións que impeleron a Avelino Díaz a escribir da maneira en que o fixo e os estímulos que animaron a súa poesía.

Cando regresa a Galicia en 1916, a vocación de AD parece ser a de mestre. Pode tamén ser que o traballo de ensinante obedeza igualmente a algo lexítimo: sobrevivir. A súa formación fora autodidacta. Non se sabe que tentara publicar poesía antes de 1924. No Inquérito xa mencionado confesa que comezou a escribir de rapaz ("Empecei, de rapáz, a esquirbir "versitos" en castelán", di AD), e a seguir aclara: "Épocas da propia obra: Do 1924 hastra hoxe. (...) O pubricado: Unhas cen composicións. illadamente en revistas e periódicos galegos" (Acuña Trabazo e Alonso Montero, 2008).
Parece claro que dende novo a poesía exerce nel algún atractivo, mais ata os 27 anos non semella que sentise a urxencia de verse publicado. Se botamos unha ollada á súa biografía e, en concreto, ó seu pasado de neno orfo de pai, é posible apuntar un escenario que animase a súa natural inclinación para a poesía. En 1916 déixase de publicar o xornal agrarista de maior arraigo na comarca, El Agricultor, de cuxa redacción formaba parte o pai que nunca o recoñecera como fillo lexítimo, Manuel María García Castro. García Castro era o poeta oficial da revista mensual que se levaba publicando dende 1907. En 1910, con 12 anos, cando marcha cun parente seu a Bos Aires, o adolescente sabía da sona local e das veleidades poéticas do seu pai que estudara en Mondoñedo - pero que non o estuda a el.

Como queira que isto fose, unha explicación "psicanalítica" como a esbozada -de querer emular o pai para gañar o seu recoñecemento- diría máis ben pouco da súa perseveranza e sobre todo da diferenza abismal entre os versos festivos e ás veces reivindicativos de García Castro e a sensibilidade lírica netamente diferente de Avelino Díaz. A maneira en que se estimularon as súas potencialidades habería que buscalas no novo ambiente da emigración, na apertura de miras que ela supuxo, nas experiencias coa sociedade local que axuda a fundar e que o acaba adoptando e promocionando como "o poeta de Meira", apelativo co que será coñecido entre a colectividade galega. $\mathrm{Da}$ súa sociedade local ha de acabar dando o salto á Federación de Sociedades, á practica regular do xornalismo, ás reunións e tertulias con escritores arxentinos e galegos que o incitan a publicar nas súas revistas, e a oficiar de poeta en eventos e ocasións do máis variado.

Hai ademais en $\mathrm{AD}$ o elemento autóctono e popular co que se identifica por extracción social e por unha inquebrantable vontade de fidelidade ás súas orixes. Certo que a poesía de $\mathrm{AD}$ non é, en esencia, costumista e folclórica

${ }^{6}$ A suposta fonte de Álvarez Limeses para a súa pregaria foi destacada por Carballo Calero (1985: 498499) na súa breve reseña do escritor pontevedrés. 
-aínda que ten poemas nos que cultiva esta faceta, que nunca abandonou- pero a asimilación dos ritmos, métricas e formas populares durante a infancia parece estar patente na especial cadencia melódica e musical que caracteriza os seus versos. A sincera adhesión ó pobo, a quen invoca e exhorta en moitos dos seus poemas de rebeldía, verase correspondida polo aprecio da propia comunidade galega de Bos Aires que o agasallaría en varias ocasións. O pobo de Galicia e o anhelo da súa liberación foi sen dúbida o maior estímulo para a súa poesía patriótica e de reivindicación política.

Que motivacións levan a un poeta a identificarse cun grupo? Por que cantar un pobo aldraxado e alienado que non acaba de ter conciencia de si, a unha raza obxecto de desdén e burlas forzada a emigrar por deprivación económica, a un país que agora soporta, ademais da sempiterna miseria e explotación, a violencia e represión fascista, a tristes emigrantes que deixan as súas aldeas e se enfrontan á morriña lonxe da terra, a simples labregos, campesiñas, pallaregas e pastoras que sobreviven de milagre, a meniños pobres, inxenuos e indefensos, a gaiteiros asasinados...? Enunciados así os temas da pregunta a modo de catálogo de desgrazas colectivas, un podería pensar que se trata dunha lectura anacrónica dun poeta co que o crítico se pode conceder certas licenzas. Hai outros Avelinos, mais este destaca pola súa relevancia.

Cando se poidan ler os seus versos, os lectores poderán experimentar se a súa é unha impostura literaria ou se senten real a solidariedade que manifesta cos indefensos ou magoados pola vida e cos que sofren inxustizas; poderán decidir se a tenrura case inxenua pola máis sinxela planta ou paxariño é sincera, ou se é verdadeira a empatía coa máis triste das mulleres a quen o mozo acaba de deixar para probar sorte da outra banda do mar. Como persoa de moral íntegra que se forxara a si mesma a través do traballo, por concienciación e identificación coas clases máis humil$\mathrm{des}^{7}$, por amor propio e amor ós seus, Avelino Díaz está suficientemente arroupado e motivado para abordar a alienación e o desarraigo como materias poéticas, para buscar as raíces da identidade no tempo e lugar que estima máis auténticos e, ademais, para o facer na lingua humillada que el reclama no pasado ser de reis e de sabios e á que, no presente, lle recoñece mellor sorte no Brasil e Portugal. Unha boa parte do seu legado ten a impronta ben intencionada da poesía civil e de redención escrita para un pobo que sente escravizado, para espertalo, animalo e instalo a que se libere.

A xente entende hoxe que a deprivación económica é causa de inxustizas sociais. Non hai tanta xente que comprenda outra deprivación á que unha boa parte da humanidade se ve sometida: a deprivación da lingua. A deprivación de poder usar a lingua propia forma parte desa indefensión máis xeral e é unha experiencia que todos os pobos colonizados e todos os inmigrantes coñecen ben: a lingua que nun lugar ou nun momento valía de repente deixa de valer. O Avelino de Debezos que escolma o que acha mellor do que fixera era absolutamente consciente do descubrimento da importancia da lingua propia. Nese intre, os galegos de Bos Aires claman ante a ONU, fronte á España de Franco, contra a represión que se exerce sobre o galego. $\mathrm{O}$ amor pola lingua nai é evidente en moitos poemas do seu primeiro libro en galego, Debezos. AD sabe que todas as linguas serven para o mesmo, para ir ó encontro dos seus falantes, e para compartir con eles a súa maxia e beleza. En "Cousas do Ceio", o meniño galego que morre e chega ó ceo deixa abraiado ó mesmo Deus ó lles aprender ós anxos o seu "falar meigo". En "Cantares" (1947b: 47-48), asoma o Avelino moralista: a doce linguaxe é un imperativo moral dos bos galegos: é de bos fillos, falala; mais...

\footnotetext{
${ }^{7}$ En termos económicos, a súa experiencia é a de milleiros de traballadores na emigración que conseguen vivir dun salario e soster a súa familia. El mesmo confesa no poema "Destino" de Flor de retama (1947a: 7): "Mi suerte nada tuvo de mala ni de buena:/ no me mostró risueño semblante la fortuna/ ni fue, tal vez, del todo severa su condena".
} 
Galego que se esqueceu

de falar na nosa lengua

que fuxa lonxe de nós

ou que volva deprendela.

Apaixonado bardo da nación e lingua galegas, home íntegro e de principios firmes, galeguista e republicano, Avelino é, na diáspora arxentina, o poeta da patria, o poeta da liberación nacional e popular en liña cos escritores dos movementos de liberación que xurdirán nos países en vías de descolonización finalizada a II Guerra Mundial. Algúns dos seus poemas escritos nestes anos son, visiblemente, os últimos poemas de combate e de incitación á loita armada contra Franco. Na Arxentina e en México, os exiliados republicanos esperaban que americanos e británicos acabasen con Franco, o último dos baluartes do fascismo en Europa. A actitude combativa dos poemas destes anos xustifícase nese contexto posbélico mundial.

\section{CAPACIDADE / APTITUDE / HABI- LIDADE / TALENTO}

Da actitude para a aptitude. O cuarto tipo de restricións ós nosos actos de identidade, segundo LePage e Tabouret Keller (1985) ten que ver coas habilidades que somos quen de despregar para modificar a nosa forma de comportarnos. Quen podemos ser depende das nosas capacidades e dos nosos talentos.

Visto dende a vantaxe que nos dá a nosa perspectiva temporal, en 1947 , con xusto 50 anos, AD encóntrase no cumio das súas potencialidades creativas. É capaz de autoeditar dous libros e a comunidade para a que tanto levaba traballado homenaxéao en dúas ocasións (Freire Freire 2002: 43-49). A Agrupación de Artistas Galegos faino en novembro; a Irmandade Galega, o equivalente ó Partido Galeguista no exilio, fai o propio en decembro. Neste segundo evento participarán Manuel Puente, Rey Baltar e o propio Castelao, que eloxia $\mathrm{AD}$ e a súa obra con sentidas palabras ó final do acto. Son as fotos máis reproducidas da súa persoa. Os 35 poemas que lle adicou a Castelao dende o seu pasamento en 1950 dan fe do mutuo recoñecemento e aprecio.

É en Debezos, onde probablemente a identidade social, en forma de rebeldía ante a inxustiza, e o talento natural do poeta se amosan ó lector de maneira máis nidia. A pesar do ánimo tranquilo e sereno en que todas as semblanzas contemporáneas concordan, só se teñen que ler as poesías en que o autor expresa a súa posición social e política para descubrir o seu carácter enérxico, decidido e inequivocamente comprometido coas ideas que defende. Na cuestión do Inquérito de 1936 que envía a Filgueira referida ós criterios que deben rexer a escolma planeada polo Seminario de Estudos Galegos, Avelino, cunha mentalidade aberta e respectuosa por todas as tendencias poéticas do momento, suxire aceptar nela todo tipo de orientacións pero non ten inconveniente en destacar o grupo de poetas cos que se sente máis identificado:

Deben fegurar na antoloxía todos os poetas cuia obra seia de algun porveito pra Galicia, calquera seia a sua ourentación, política, social, relixiosa etc; abonda pra elo que seian galegos de alma e corazón. Se eu tivese o honor de figurar na antoloxía, quixera ser situado perto dos poetas mais rebeldes. (Acuña Trabazo e Alonso Montero, 2008)

Os poemas de rebeldía, de denuncia, de exhortación á mobilización, de loita contra a opresión e de homenaxe ós mártires constitúen a parte máis notoria da primeira parte de Debezos rubricada baixo o nome de "Terra a nosa". Os títulos, "Rebélate", "Érguete, pobo", "A loita", "Invocación", "Sete casas" ou "Carral" falan dun AD rexo, comprometido, e identificado coa sorte do seu pobo, coa súa liberdade e coa súa lingua. "Rebélate" (1947b: 19-21) é un dos poemas representativos desta tendencia que nel bascula entre a insurxencia e o acento íntimo ó que nunca renuncia ${ }^{8}$.

\footnotetext{
${ }^{8}$ É curioso que este poema, que López García (2014) localizou no Galicia do 22 de marzo do 1936 , fose escrito xusto uns días despois de que lle escribise a Filgueira (con data de 17 de marzo de 1936) reclamándose próximo dos "poetas rebeldes".
} 
¡Pobo meu...!

Non te poñas a chorar

agora, nin te laiar

dos males qu-estás sufrindo.

O laiarse é cobardía;

érguete con valentía.

Cando se quer adiantar

e dos nemigos trunfar

hai que ter xesto varil

e loitar, pois quen se deixa

vencer sen loita, e se queixa

a mais de cobarde, é vil.

(...)

Escoita, meu pobo, escoita:

somentes na recia loita

se fan esforzados peitos.

Quen era este Avelino que rima "escoita" con "loita", reflexión e acción, durante case catro décadas a $5000 \mathrm{~km}$ de Galicia? Neira Vilas, que o coñeceu en vida, deixouno dito na crónica que Nora Longhini (2008: 51) recuperou para nós da maneira máis clara e sintética posible: "Un bo poeta". E, como se aínda quixese intensificar a apreciación, engadiu: "un excelente versificador". Dise que o talento é o don que nos vén dado, pero sendo como é un potencial deberá, se fixermos caso das dúas parábolas do novo testamento ${ }^{9}$, ser usado e desenvolvido. Na única historia literaria en que se menciona o nome de Avelino Díaz, na de Méndez Ferrín (1984: 58), ponse de relevo o seguinte: "autor de pezas de gran rigor expresivo", de xeito que ademais da expresividade, do seu talento expresivo, Ferrín destaca a rigorosidade, o rigor emparentado coa precisión, coa exactitude, coa corrección, coa fiel e coidada representación que só se adquire a través da práctica dunha conduta estrita. Nalgún momento, Avelino decidiu vivir poeticamente e escolleu, con humildade, o camiño da poesía (Freire Freire 2002):

Son, a mais d-asalariado, periodista d-afición, poeta por vocación sin ser por eso nomeado.
Se, tras revisar os seus poemas, houbese que engadir algo definitorio do seu talento literario, sen dúbida o trazo que habería que salientar da súa poética é o seu romanticismo, a voz do humilde, solitario e independente "eu" poético dende a que fai rimar os seus versos. A súa poesía, a partes iguais convencional e persoal, segue a súa senda autobiográfica, veladamente ás veces, pero case sempre imbuída de elementos narrativos e memorísticos. Neles sentimos aquilo polo que agoniza -o desarraigo e separación das orixes e o estrañamento do pasado, "a patria da alma" en verbas do seu adorado Heinrich Heine- e participamos do que máis anhela -dos seus desexos (a liberación da patria física), ilusións (o retorno a ela), fantasías (voar, viaxar...), devezos, ansias, azos... Desprazándose do persoal para o social, a súa é unha comunicación pasional que vai dos sentidos ós sentimentos e do amor devoto polo popular ó compromiso co político. A alma de Avelino é romántica e soñadora: soña coa rebelión da terra, e imaxina improbabilidades coma regresar ó seu "recanto nativo". O seu primeiro libro é Debezos, e no seu último libro, Pallaregas, o poema de igual título "Debezos" (1947b: 64-65) comeza con estas dúas estrofas:
$¡ A i$, quen andoriña fose e quen puidese deixar os coñecidos espazos pra poder ir esculcar debezidos hourizontes n-algún país estelar! Ter diante novos camiños e non podel-os andar; ver como se vai o río correndo de car-ó mar e deixalo que se vaia sin podel-o acompañar.

Na poesía de Avelino, como en xeral na literatura do exilio e da emigración, o tema do retorno, da volta ansiada, é motivo recorrente. Posto que facelo fisicamente é imposible, o poeta pode polo menos sublimar literariamente

${ }^{9}$ Mateo 25.14-30, Lucas 19.12-28. 
o desexo de voltar ou de moverse libremente. O soneto "Volveré" é o segundo poema do seu primeiro libro Flor de retama. "Destino", o terceiro. Se examinamos a secuencia desta apertura poética, a ordenación parece significativa: "Proa" (dirección) - "Volveré" (anhelo) - "Destino" (fin, propósito, pero tamén "fado, sino"): "Volveré" (1947a: 6) reza así:

Volveré por el camino

por donde fuí siendo mozo

con este leve retozo

de mi vivir vespertino.

É o final anhelado que nunca chegou a facerse realidade.

\section{CONCLUSIÓNS}

Versos rimados en galego en Bos Aires. Que é o que motiva a un poeta? Que estraña teimosía mantén a lealdade de catro décadas facendo poesía romántica e existencial? Que é o que move unha persoa a traballar de proletario para manter a familia e a manterse escribindo tenazmente para un futuro incógnito que a ninguén se revela?

Dende 1939 ata mediados de 1960, Bos Aires foi a capital da cultura galega. Estes son os anos de maior produtividade poética e periodística de Avelino Díaz. En 1947, cando se publica Debezos, a capital arxentina andaba polos cinco millóns. Deles, medio millón eran de ascendencia galega. Para a maior parte deles, Bos Aires fora o primeiro contacto cunha urbe moderna e cosmopolita. Avelino arriba a Bos Aires en 1910 a primeira vez, e en 1922 a segunda e definitiva. Castelao chega dende Nova York en xullo de 1940. Ningún dos dous volvería con vida a Galicia. Castelao encontra en Montevideo e en Bos Aires unha Galicia non vencida que o agarda con respecto e esperanza. Esa Galicia era o froito do traballo de galeguistas coma Avelino Díaz.
Libros, emisións radiofónicas, grupos e escolas de teatro, grupos corais e de baile, xornais, organizacións societarias, políticas e xuvenís, activismo. En 1950 para pesar dos galegos da diáspora e de Avelino, en particular, morre Castelao. Seis anos despois celébrase o evento singular do I Congreso da Emigración, do que Avelino Díaz será secretario. Blanco Amor publica A Esmorga en 1959. Neira Vilas, as Memorias dun neno labrego en 1961. Pallaregas publícase en 1963. Suárez Picallo, o indutor de que o noso Avelino escribise en galego, morre en 1964. Avelino, en 1971. Os 11 poemas a Castelao, póstumos, aparecen en 1975.

Esta contribución pretendeu indagar na comprensión e posibilidades de apertura da súa poesía. O máis particular do noso caso é o feito de que se trata dun poeta "desaparecido" para a literatura galega e dunha poesía materialmente "ilocalizable". Un poeta "desaparecido" no sentido de perdido para os lectores galegos durante anos, e "ilocalizable" no sentido de inaccesible por tratarse dun autor e dunha poesía que nunca conseguiron arribar a esta beira do Atlántico. A poesía de Avelino Díaz foi lida, recitada, cantada, musicada, escoitada, coñecida e apreciada polos galegos de Bos Aires durante as dúas décadas que acabamos de sumarizar, pero ignorada no país ó que cantaba, porque a liberdade deste e das súas xentes fora aniquilada.

$\mathrm{Na}$ análise da identidade que se propuxo ó comezo destas páxinas facíase fincapé na identificación do "outro" como parte indispensable do proceso de construción de calquera identidade. O "outro", aquel que non é "un mesmo", "o que non son eu", "o que aínda non somos nós", o descoñecido, foi nesta contribución o propio Avelino Díaz. Foi o propósito destas páxinas elaborar algunhas das ideas que contribúan á interesarnos pola súa obra e a facer que ese "outro" sexa algo máis "noso". 


\section{REFERENCIAS BIBLIOGRÁFICAS}

Acuña Trabazo, Ana e Xesús Alonso Montero (2008): Os Poetas galegos (1936): antoloxía consultada. Pontevedra: Museo de Pontevedra.

Carballo Calero, Ricardo (1981): Historia da literatura galega contemporánea (1808-1936). Vigo: Galaxia.

Díez De Revenga, Francisco Javier (2005): "Poesía y mito: la recepción de don Quijote en la lírica de la Edad de Plata", Príncipe de Viana. Leyendo el Quijote 66/236, pp. 713-726.

DíAz, Avelino (1947a): Flor de retama. Buenos Aires: Establecimiento Gráfico Tasca y Cia.

— (1947b). Debezos. Buenos Aires: Imprenta de José Rosenbaum.

(1963): Pallaregas. Buenos Aires: Imprenta de Cabrera y Rey.

(1975): 11 poemas a Castelao. Buenos Aires: Centro Lucense.

Fernández Salgado, Benigno (1994): "Lingua, economía e tolerancia. Entrevista con Robert B. LePage", Grial. Revista galega de cultura 32/117, pp. 27-46.

(ed.) (2007). El Agricultor. Revista de agricultura: órgano de la "Sociedad de Labradores y Agricultores" de Riotorto; y "Unión Agrícola y Pecuaria" de Villaodrid y Villameá. Santiago: Xestión do Xacobeo.

Freire Freire, Marivel (1999): “Avelino Díaz e Castelao”, en X. L. Axeitos e C. Portela Yáñez (eds.), Sesenta anos despois. Os escritores do exilio. Sada: Ediciós do Castro, pp. 339-359.

(2002): Avelino Díaz. Unha voz comprometida na Galicia emigrante. Lugo: Brigadas en Defensa do Patrimonio Chairego.

GLASERSFElD, Ernest von (1995): Construtivismo radical. Uma forma de conhecer e aprender. Lisboa: Instituto Piaget.

LePage, Robert B. e Andrée Tabouret-Keller (1985): Acts of Identity. Creole-based Approaches to Language and Ethnicity. Cambridge: CUP.

Longhini, Nora (2008): Neira Vilas. Os anos da Arxentina 1949-1961. Textos recuperados. Vigo: Galaxia.

LóPez, Xosé (2015): “Avelino Díaz. Ecos do xornalismo comprometido", en Homenaxe a Avelino Díaz, poeta e xornalista na diáspora americana. Contribucións académicas dende Galicia (no prelo).

Martínez-Romero Gandos, José V. (2005): Psicología y emigración. Alteridad y aliencación en el emigrante gallego al Río de la Plata. Su comprensión existencial. Tese de doutoramento inédita. Buenos Aires: Universidad del Salvador.

(2012): "Identidad lingüística y sentido de la vida: un análisis fenomenológico" (dispoñíbel en: https://www.academia.edu/2637873/Identidad_linguistica_y_sentido_de_vida_un analisis fenomenologico).

NeIra Vilas, Xosé (1963): “Don Avelino y Cuba”. España Republicana. A Habana.

Méndez Ferrín, Xosé Luís (1984): De Pondal a Novoneyra. Poesía galega posterior á guerra civil. Vigo: Xerais.

Vigotsky, Lev (1962): Thought and Language. Cambridge, Massachusetts: MIT Press. 